\title{
REACTIONS OF FERROUS AND FERRIC IONS WITH HYDROGEN PEROXIDE
}

\author{
By W. G. BARB, J. H. BAXENDALE, PHILIP GEORGE and K. R. HARGRAVE
}

Chemistry Department, University of Leeds

$I^{\mathrm{N}}$ $\mathrm{N}$ the elucidation of the mechanism of the reactions between hydrogen peroxide and ferrous and ferric ions, a consider tble advance was made by Haber and Weiss $^{2}$, who gaggested that the highly reactive intermediates which have been shown to be present were the radical $\mathrm{HO}$ and $\mathrm{HO}_{2}$. Their mechanisms, recently revised oy Weiss ${ }^{2}$, are as follows:

$$
\begin{aligned}
& \not \mathrm{Fe}^{2+} \text { reaction } \\
& \mathrm{Fe}^{2+}+\mathrm{H}_{2} \mathrm{O}_{2} \rightarrow \mathrm{Fe}^{3+}+\mathrm{OH}^{-}+\mathrm{HO} . \\
& \mathrm{H}_{2} \mathrm{O}_{2}+\mathrm{HO}^{-} \rightarrow \mathrm{H}_{2} \mathrm{O}+\mathrm{HO}_{2} \\
& \mathrm{H}_{2} \mathrm{O}_{2}+\mathrm{HO}_{2} \rightarrow \mathrm{O}_{2}+\mathrm{H}_{2} \mathrm{O}^{-} \mathrm{HO} . \\
& \mathrm{Fe}^{2+}+\mathrm{HO}_{2} \rightarrow \mathrm{Fe}^{3+}+\mathrm{HO}_{2}^{-} \\
& \mathrm{Fe}^{2+}+\mathrm{HO} \cdot \rightarrow \mathrm{Fe}^{3+}+\mathrm{OH}^{-} \\
& \mathrm{Fe}^{3+} \text { reaction } \\
& \mathrm{H}_{2} \mathrm{O}_{2} \\
& \mathrm{Fe}^{3+}+\mathrm{HO}_{2}^{-} \rightarrow \mathrm{Fe}^{+}+\mathrm{HO}_{2}^{--} \\
& \mathrm{H}_{2} \mathrm{O}_{2}+\mathrm{HO}_{2} \rightarrow \mathrm{H}_{2}+\mathrm{H}_{2} \mathrm{O}^{2}+\mathrm{HO} . \\
& \mathrm{Fe}^{2+}+\mathrm{HO}^{-} \rightarrow \mathrm{Fe}^{3+}+\mathrm{OH}^{-} \\
& \mathrm{OH}^{-}+\mathrm{H}^{+} \rightarrow \rightarrow \mathrm{H}_{2} \mathrm{O}
\end{aligned}
$$

The reaction with the ferrous ion is seen to involve chains with $\mathrm{HO} \cdot$ and $\mathrm{HO}_{2}$ as carriers; the ferric ion reaction consists of a sequence of radical reactions. In both cases oxygen is evolved by $\mathrm{HO}_{2}$ reacting with hydrogen peroxide.

We have made an extensive experimental investigation which has revealed several new facts incompatible with the above scheme for the ferrous ion reaction. We conclude that the reaction producing oxygen is not that of $\mathrm{HO}_{2}$ with hydrogen peroxide, but $\mathrm{HO}_{2}$ or $\mathrm{O}_{2}^{-}$with the ferric ion, and we propose a chain reaction involving $\mathrm{HO}_{2}, \mathrm{HO} \cdot$ and $\mathrm{Fe}^{2}{ }^{\mathrm{F}}$ as carriers. The same chain mechanism will interpret satisfactorily both the ferrous and the ferric reactions.

The following is a summary of our observations on the ferrous ion reaction.

\section{Ferrous Ion Reaction}

It has previously been found that with low $\mathrm{H}_{2} \mathrm{O}_{2} / \mathrm{Fe}^{2+}$ ratios and in acid solutions the reaction is second order and the overall stoichiometry is $2 \mathrm{Fe}^{2+} \equiv \mathrm{H}_{2} \mathrm{O}_{2}$. When an excess of a polymerizable vinyl compound is present, the reaction is still second order in ferrous ion and hydrogen peroxide, but the stoichiometry changes to $\mathrm{Fe}^{2+} \equiv \mathrm{H}_{2} \mathrm{O}_{2}$. Under these conditions polymerization occurs and the polymer has terminal hydroxyl groups. These observations are good evidence that the following reactions occur ${ }^{3}$ :

$$
\begin{aligned}
& \mathrm{Fe}^{2+}+\mathrm{H}_{2} \mathrm{O}_{2} \rightarrow \mathrm{Fe}^{3+}+\mathrm{OH}^{-}+\mathrm{HO} . \\
& \mathrm{Fe}^{2+}+\mathrm{HO} \cdot \rightarrow \mathrm{Fe}^{3+}+\mathrm{OH}^{-} \\
& M+\mathrm{HO} \rightarrow \mathrm{HOM} \rightarrow \rightarrow \text { polymer }
\end{aligned}
$$

In the absence of substrate the rate equation is

$$
-d\left[\mathrm{Fe}^{2+}\right] / d t=2 k_{0}\left[\mathrm{Fe}^{2+}\right]\left[\mathrm{H}_{2} \mathrm{O}_{2}\right] \text {. }
$$

However, although at low $\mathrm{H}_{2} \mathrm{O}_{2} / \mathrm{Fe}^{2+}$ ratios monomers are polymerized, leuco dyestuffs oxidized to the dye, and certain dyes destructively oxidized, thus confirming the presence of the radical $\mathrm{HO}$, we have found that at the same concentrations of ferrous ion and substrate these reactions do not occur with high concentrations of hydrogen peroxide.

It is clear that under these conditions another competitor for $\mathrm{HO}$. is present, and the observations can be explained if $\mathrm{HO}$. reacts with hydrogen peroxide to give $\mathrm{HO}_{2}$. The $\mathrm{HO}_{2}$ radical thus formed is apparently unable to open the double bond of a vinyl compound or to oxidize the other substrates.

With high $\mathrm{H}_{2} \mathrm{O}_{2} / \mathrm{Fe}^{2+}$ ratios, oxygen is evolved on the addition of ferrous ion to hydrogen peroxide, which means that the stoichiometry is no longer $2 \mathrm{Fe}^{2+} \equiv \mathrm{H}_{2} \mathrm{O}_{2}$ and other reactions enter in addition to (o) and (1) above. The following results obtained in perchloric acid solutions from $p \mathrm{H} 1$ to $p \mathrm{H} 3$ enable the mechanism of reaction in this $p H$ range to be deduced.

(1) Ferrous Ion Kinetics. With concentrations of ferrous ion of approximately $10^{-5} M$ and hydrogen peroxide less than $10^{-3} M, d\left[\mathrm{Fe}^{2+}\right] / d t$ can be measured by determining the concentration of ferrous ion, $\left[\mathrm{Fe}^{2+}\right]$, colorimetrically with dipyridyl. Peroxide can be estimated by adding to excess acid $\mathrm{Fe}^{2+}$ or as pertitanic acid. Provided $2\left[\mathrm{Fe}^{2+}\right]>\left[\mathrm{H}_{2} \mathrm{O}_{2}\right]$ initially, the reaction is second order throughout with $2 \mathrm{Fe}^{2+} \equiv \mathrm{H}_{2} \mathrm{O}_{2}$. This holds up to $p \mathrm{H} 3$. At high $\mathrm{H}_{2} \mathrm{O}_{2} / \mathrm{Fe}^{2+}$ ratios the reaction initially follows the normal second-order course; but the 'rate constant' $k_{\text {obs. }}$ decreases as the reaction proceeds. This effect is shown in Fig. 1, curves $(a)$ and $(b)$, where the results are plotted as for a second-order reaction with hydrogen peroxide in great excess. Values of $k_{\text {obs. }}$ which are less than half that of the overall normal constant $2 k_{0}$ are obtained. For a given

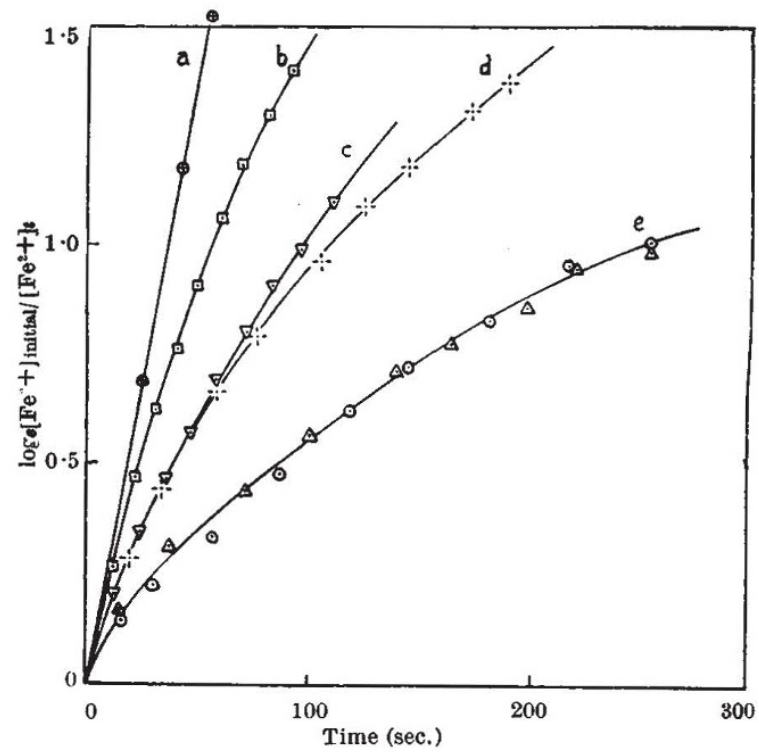

Fig. 1. Course of $\mathrm{Fe}^{2}++\mathrm{H}_{2} \mathrm{O}_{2}$ reaction with initial concentrations $1.4 \times 10^{-3} \mathrm{Fe}^{2}+$ and $29.5 \times 10^{-8} M \mathrm{H}_{3} \mathrm{O}$, at $25^{\circ} \mathrm{C}$., and $p \mathrm{H} 2 \cdot 65$ except in $(a)$. In no case is more than 10 per cent of the hydrogen peroxide used over the time interval shown. (a) N/2 HClO4; (b) no additions: (c) initially $4.6 \times 10^{-5} M \mathrm{Fe}^{3}+$

(d) initially $1.4 \times 10^{-6} M \mathrm{Cu}^{2}+$ : $^{-6}$ initially $2.4 \times 10^{-3}(\triangle)$ and $1.2 \times 10^{-3} M \mathrm{Fe}^{3}+(\odot)$ 


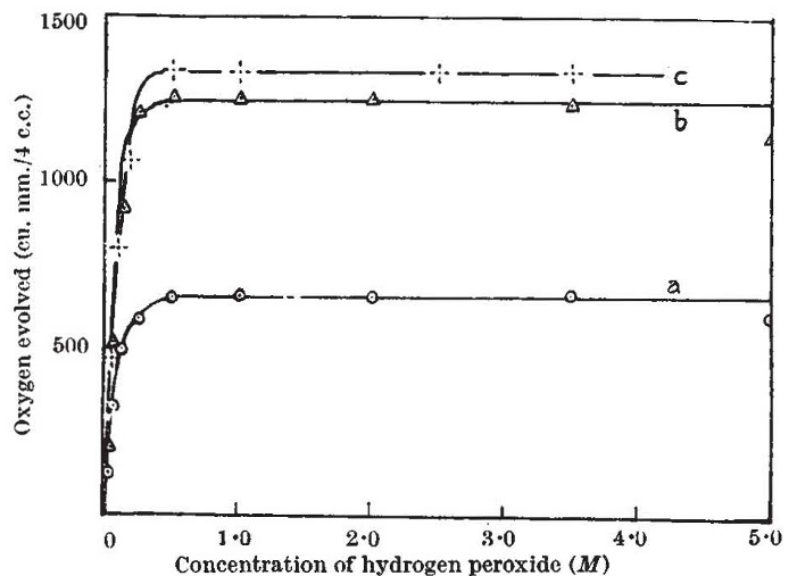

Fig. 2. Oxygen evolution from the reaction $\mathrm{Fe}^{2+}+\mathrm{H}_{2} \mathrm{O}_{2}$ at various concentrations of hydrogen peroxide. $(a) p \mathrm{H} 1.5 ;(b) p \mathrm{H}$ $1.8 ;(c) p \mathrm{H} 1.5$ with $4 \times 1 c^{-2} M \mathrm{Fe}^{3}+$ initially. Initial $\mathrm{Fe}^{2}+$, $4 \times 1 c^{-2} M$ in each case

initial concentration of ferrous ion, these deviations from second order increase with hydrogen peroxide concentration until eventually the effect of increasing the peroxide reaches a limit. This is paralleled by the dependence on the peroxide concentration of the total amount of oxygen evolved as the ferrous ions are oxidized to ferric ions given in (2) below.

Moreover, the course of a reaction from any time $t$ onwards can be reproduced $a b$ initio only with solutions of the same concentrations of hydrogen peroxide, ferrous ions and also ferric ions as at time $t$, but not with solutions containing the same concentrations of peroxide and ferrous ions alone.

(2) Oxygen Evolution. The total amount of oxygen evolved as the ferrous ion is oxidized to the ferric is easily determined from an oxygen evolution - time plot by extrapolating the linear portion, due to the subsequent catalysis of ferric ions back to zero times. Above a certain $\mathrm{H}_{2} \mathrm{O}_{2} / \mathrm{Fe}^{2+}$ ratio it is found to be independent of the concentration of hydrogen peroxide and varies approximately inversely with the concentration of hydrogen ions over the range $p$ H 1-2 (Fig. $2(a)$ and $(b))$.

(3) Effect of Ferric or Cupric Ions. If ferric ions are added to a reaction mixture, the total oxygen evolved as ferrous ions are oxidized is greatly increased, and $k_{\text {obs. }}$ is less than $2 k_{0}$ even at the beginning of a reaction. The same effect is observed with cupric ions, with the striking difference that the cupric ion is more efficient than the ferric (see Figs. 1 $(c)$ and $(d)$ and $2(c)$ ). This effect at first increases with increase of ferric or cupric ion; but we find that for any given concentration of hydrogen peroxide and ferrous ion, the evolution of oxygen and deviations from second-order reaction are unaffected by further additions of ferric or cupric ions beyond a certain amount (see Fig. $\mathrm{I}(e)$ ). In addition, at $\mathrm{H}_{2} \mathrm{O}_{2} / \mathrm{Fe}^{2+}$ ratios where the evolution of oxygen is normally independent of the concentration of hydrogen peroxide, it increases with the latter when these limiting amounts of ferric or cupric ions are present. Similarly, the limiting deviations from second order at high concentrations of hydrogen peroxide described in (1) above are no longer observed at sufficiently high concentrations of ferric and cupric ions.

(4) Effect of Fluoride Ions. In the presence of fluoride ions, the total evolution of oxygen is decreased and a system which would have shown deviations from second-order kinetics no longer does so.
From the observations described in (1)-(4), we conclude that : (a) The oxygen is not evolved as the result of a reaction between $\mathrm{HO}_{2}$ and hydrogen peroxide, with a terminating reaction between ferrous ions and $\mathrm{HO} \cdot$ or $\mathrm{HO}_{2}$. In these cases, it would always increase with the concentration of hydrogen peroxide, whereas we find it reaches a limiting value.

(b) The oxygen is evolved in a reaction involving ferric (or cupric) ions. This is probable because of the increase obtained by addition of these ions, and the decrease when ferric ions are removed by fluoride.

(c) Ferrous ions are regenerated by the oxygen evolution reaction. This is probable because we have found that at high $\mathrm{H}_{2} \mathrm{O}_{2} / \mathrm{Fe}^{2+}$ ratios, $k_{\text {obs. }}$ can be much less than $k_{0}$, the value it would have if all reactions involving ferrous ions, other than the primary step (o) above, were eliminated (see ref. 3). Hence ferrous ions must be regenerated during the reaction. Further, $k_{\text {obs. }}$ is even smaller, and thus ferrous ions are regenerated more rapidly when ferric (or cupric) ions are present initially, that is, under the conditions for increased oxygen evolution. The most probable reaction to account for these observations is one between $\mathrm{Fe}^{3+}$ or $\mathrm{Cu}^{2+}$ and $\mathrm{HO}_{2}$.

(d) Another reaction which removes ferrous ions occurs in addition to reaction (1) above. This is required because the qualitative experiments with substrates suggest that most $\mathrm{HO}$ - reacts with hydrogen peroxide at high $\mathrm{H}_{2} \mathrm{O}_{2} / \mathrm{Fe}^{2+}$ ratios, and hence $\mathrm{Fe}^{2+}+\mathrm{HO} \cdot$ is no longer a significant reaction. But in spite of this, the ferrous ions are still removed initially at a rate which corresponds to that at low $\mathrm{H}_{2} \mathrm{O}_{2} / \mathrm{Fe}^{2+}$ ratios, that is, $k_{\text {obs }}$. is always initially equal to $2 k_{0}$ in the absence of added ferric ions. The kinetics can be accounted for if the additional reaction is between ferrous ions and $\mathrm{HO}_{2}$.

Reaction Scheme. From these considerations we propose the following reaction scheme :

$$
\begin{array}{ll}
\mathrm{Fe}^{2+}+\mathrm{H}_{2} \mathrm{O}_{2} \rightarrow \mathrm{Fe}^{3+}+\mathrm{OH}^{-}+\mathrm{HO} \cdot & k_{0} \\
\mathrm{Fe}^{2+}+\mathrm{HO} \cdot \rightarrow \mathrm{Fe}^{3+}+\mathrm{OH}^{-} & k_{1} \\
\mathrm{H}_{2} \mathrm{O}_{2}+\mathrm{HO} \cdot \rightarrow \mathrm{H}_{2} \mathrm{O}+\mathrm{HO}_{2} & k_{2} \\
\mathrm{Fe}^{2+}+\mathrm{HO}_{2} \rightarrow \mathrm{Fe}^{3+}+\mathrm{HO}_{2}^{-} & k_{3} \\
\mathrm{Fe}^{3+}+\mathrm{HO}_{2} \rightarrow \mathrm{Fe}^{2+}+\mathrm{O}_{2}+\mathrm{H}^{+} & k_{4}
\end{array}
$$

At very low $\mathrm{H}_{2} \mathrm{O}_{2} / \mathrm{Fe}^{2+}$ ratios, only steps (o) and (1) occur, the reaction is second order and the evolution of oxygen is zero. As the ratio increases, the course of reaction is determined by competition for $\mathrm{HO}$ - in (1) and (2); hence the evolution of oxygen and deviations from second-order kinetics increase with the concentration of hydrogen peroxide. At high $\mathrm{H}_{2} \mathrm{O}_{2} / \mathrm{Fe}^{2+}$ ratios, the competition for $\mathrm{HO}_{2}$ in (3) and (4) predominates, and since these do not involve hydrogen peroxide, the oxygen evolved and the kinetic deviations become independent of the concentration of hydrogen peroxide. The effect pro. duced by cupric ions can be explained if they react more readily than ferric ions in (4), and we have

$$
\begin{aligned}
& \mathrm{Cu}^{2+}+\mathrm{HO}_{2} \rightarrow \mathrm{Cu}^{+}+\mathrm{O}_{2}+\mathrm{H}^{+} \\
& \mathrm{Cu}^{+}+\mathrm{Fe}^{3+} \rightarrow \mathrm{Cu}^{2+}+\mathrm{Fe}^{2+} \text { (very fast) }
\end{aligned}
$$

These two reactions amount to a catalysis of reaction (4). The limiting conditions attained in the presence of ferric or cupric ions are seen to arise when (4) or (5) predominate to such an extent that $\mathrm{HO}_{2}$ term. ination in (3) is no longer significant compared with HO . termination in (1). Under these conditions, the total oxygen evolved and $k_{\text {obs. }}$ should again be 
dependent on the concentration of hydrogen peroxide as observed.

The kinetics of the reaction and the amount of oxygen evolved are found to agree with the expressions which can be deduced from the above mechanism, and, from the kinetic analysis, values for $k_{4} / k_{3}$ and $k_{1} / k_{2}$ can be obtained. These will be discussed in a later publication. We find that $k_{1} / k_{2}$ is independent of $p \mathbf{H}$, whereas $k_{4} / k_{3}=\frac{K}{\left[\mathrm{H}^{+}\right]+\bar{K}_{1}}$ over the range examined. $K_{1}$ is found to be about $6 \times 10^{-3}$, which corresponds closely to the equilibrium constant of ${ }^{5}$

$$
\mathrm{Fe}^{3+}+\mathrm{H}_{2} \mathrm{O} \rightleftarrows \mathrm{FeOH}^{2+}+\mathrm{H}^{+} \text {. }
$$

The variation of $k_{4} / k_{3}$ with the concentration of hydrogen ions can be accounted for if the reactants in (3) and (4) are

$$
\begin{array}{ll}
\text { (i) } \mathrm{Fe}^{2+}+\mathrm{HO}_{2} \text {, and } \mathrm{Fe}^{3+}+\mathrm{O}_{2}^{-} \\
\text {or (ii) } \mathrm{Fe}^{2+}+\mathrm{HO}_{2} \text {, and } \mathrm{FeOH}^{2+}+\mathrm{HO}_{2} \\
\text { or (iii) } \mathrm{Fe}^{2+}+\mathrm{O}_{2}^{-} \text {, and } \mathrm{FeOH}^{2+}+\mathrm{O}_{2}^{-} \text {. }
\end{array}
$$

A detailed kinetic analysis shows that only the reactions in (i) occur.

\section{Ferric Ion Reaction}

The catalytic decomposition of hydrogen peroxide by ferric salts has been found to be first order both with regard to hydrogen peroxide and ferric ions, and to vary inversely as the concentration of hydrogen ions'. This kinetic form can be obtained if the initial reaction is

$$
\mathrm{Fe}^{3+}+\mathrm{HO}_{2}^{-} \rightarrow \mathrm{Fe}^{2+}+\mathrm{HO}_{2} \ldots k_{i},
$$

and is followed by reactions (0), (2), (3) and (4) in the ferrous ion scheme above. The exclusion of (1) is justified since these experiments have usually been done at high $\mathrm{H}_{2} \mathrm{O}_{2} / \mathrm{Fe}^{3+}$ ratios. This mechanism is to be preferred to that proposed by Weiss ${ }^{2}$ because it retains reactions which are necessary to explain the ferrous ion reaction, and which cannot be ignored in the ferric ion reaction. An important feature of the above scheme is that it is a chain reaction rather than a sequence of radical reactions as proposed by Weiss. Preliminary calculations using the constants derived from the study of the ferrous ion reaction indicate a chain-length of about $10^{3}$.

A recent investigation of the ferric ion reaction by Andersen ${ }^{8}$ shows that at low $\mathrm{H}_{2} \mathrm{O}_{2} / \mathrm{Fe}^{3+}$ ratios the reaction is no longer first order with regard to hydrogen peroxide, but somewhat higher. The data of Simon et al. show similar features?. The higher order can be understood if at these low $\mathrm{H}_{2} \mathrm{O}_{2} / \mathrm{Fe}^{3+}$ ratios reaction (1) becomes significant, for if (1) completely replaces (3) as a chain termination reaction, the decomposition-rate is given by

$$
-d\left[\mathrm{H}_{2} \mathrm{O}_{2}\right] / d t=k\left[\mathrm{Fe}^{3+}\right]^{1 / 2}\left[\mathrm{H}_{2} \mathrm{O}_{2}\right]^{3 / 2} \text {. }
$$

The well-established promotion by cupric ions of the ferric ion catalysed decomposition of hydrogen peroxide, which has been examined in some detail by Bohnson and Robertson ${ }^{8}$, gives further support. They observed a limiting promotion effect by cupric ions which is similar to that described above in the ferrous ion reaction and can be explained in the same way, namely, by the predominance of reaction (5) over (3), causing all chain termination to occur by reaction (1), thus making the overall reaction inde. pendent of the concentration of cupric ions. Further. more, the predicted rate expression in these con. ditions is the same as (6) above, and this is supported by the data available in that they show a dependence of the rate on the square root of the concentration of ferric ions, $\left[\mathrm{Fe}^{3+}\right]^{1 / 2}$.

These ferric ion reactions are being investigated in more detail to check the above kinetic expressions.

We are indebted to Prof. M. G. Evans for advice and helpful discussions during the course of this work.

${ }^{2}$ Haber and Weiss, Proc. Roy. Soc., A, 147, 332 (1934).

Weiss, Discussions of the Faraday Society No. 2, 212 (1947).

${ }^{3}$ Baxendale, Evans and Park, Trans. Farad. Soc., 42, 155 (1946).

4 George, Biochem. J., 43, 287 (1948).

Sabinowitz and Stockmeyer, J. Amer. Chem. Soc,, 64, 335 (1942).

- Andersen, Act. Chem. Scand., 2, 1 (1943).

'Simor., Haufe, Reetz and Preissler, Z. anorg. Chem., 230, 129 (1936).

${ }^{8}$ Bohnson and Robertson, J. Amer. Chem. Soc., 45, 2512 (1923).

\section{THE RARE ISOTOPE OF HELIUM, $\mathrm{He}^{3}$; A KEY TO THE STRANGE PROPERTIES OF ORDINARY LIQUID HELIUM, $\mathrm{He}^{4}$}

\author{
By Prof. F. LONDON \\ Duke Univershy, Durham, N.C.
}

A

VERY intereging experiment with the rare helium isotope helium-3 has recently been made by D. W. Osbory, B. Weinstock and B. M. Abraham, of the Argonne National Laboratory in Chicago'. This experinent is crucial, as it may decide the correctnes of a theory devised eleven years ago ${ }^{2}$ to explain ne peculiar properties of the fluid into which ording y liquid helium turns when cooled below the temperature of $2 \cdot 19^{\circ}$ abs. (about two degrees below its hormal boiling point of $4 \cdot 2^{\circ}$ abs.).

Above $\mathbf{2} \cdot 19^{\circ}$ abs., liquid helium behaves very much like any other liquid; it shows ordinary viscous flow, normal heat conductivity, etc. At $2 \cdot 19^{\circ}$ abs. it undergoes a strange change of state; its entropy, that is, its degree of thermal disorder, very rapidly decreases within a small temperaturerange with a discontinuity of the specific heat at $2 \cdot 19^{\circ}$ abs. ( $\lambda$-point). However, instead of solidifying as any other liquid would do if cooled to a sufficiently low temperature, liquid helium turns, below $2 \cdot 19^{\circ}$ abs., into a very peculiar kind of fluid, which has characteristically been called 'superfluid'. It no longer has an ordinary viscosity, it leaks through the finest cracks which were practically tight for helium, liquid or gaseous, above $2 \cdot 19^{\circ}$. It shows a particular transfer of heat with a facility incomparably better than any other substance. One speaks of 'heat-superconductivity'. In addition, there are many other utterly strange features by which liquid helium below $2 \cdot 19^{\circ}$ abs., called 'liquid helium II', is distinguished from all other known liquids.

The theory proposed by me in 1938 tried to relate the unique properties of liquid helium II to those of what one calls an 'ideal Bose-Einstein gas'. In 1924, Einstein $^{3}$, generalizing ideas of the Indian physicist Bose, had developed a very strange concept of a gas consisting of identical molecules, which are assumed 